\title{
CELESTINESCA
}

https://doi.org/10.7203/Celestinesca.12.19688

\section{REFLEXIONES SOBRE MI PUESTA EN ESCENA DE 'CELESTINA'}

\author{
José Osuna Lameyer \\ Director de escena \\ Madrid
}

[Nota: Estas reflexiones fueron preparadas originalmente para ser leidas en las Jornadas Literarias, encuentro de estudiosos y gente del teatro, que tuvieron lugar durante la quincena (1-15 septiembre 1988) del XI Festival Internacional de Teatro Clásico. Al saber que Celestinesca tendria especial interés en hacer llegar estas consideraciones a sus lectores, José Osuna tuvo la amabilidad de permitir que las publicásemos, una colaboración que cae perfectamente dentro del espiritu nuestro de preservar todo lo posible en estas páginas de las realizaciones escénicas de la Tragicomedia en nuestro siglo. Ed.]

\section{Palabras previas}

En el breve espacio de este comunicado no cabe, por supuesto, el planteamiento riguroso y pormenorizado de una puesta en escena; ni tan siquiera su explicación detallada. Me he limitado, pués, a insinuar algunas de sus ideas, algunos de sus momentos y algunas de las caracteristicas que más me interesaron de su contexto general y personajes; todo ello con criterios de economia en el desarrollo. Siendo la CELESTINA una obra maestra, está abierta a muchas posibles interpretaciones. Lo que yo voy a decir, a continuacion, es el esbozo de una de ellas.

\section{Comunicacion}

Repasando algunos de los textos que me sirvieron de consulta previa para mi montaje de "La Celestina", ocurrido hace cerca de 20 años, me encuentro en el prólogo de Jose Maria Maravall a su excelente estudio El mundo social de La Celestina con una muy interesante consideración que intentaré trasladar a ustedes, siquiera sea resumida.

Dice que una visión de "La Celestina" desde un punto de vista histórico-sociológico no nos permite descubrir el sentido total de la obra $y$ aboga por un trabajo interdisciplinario en el que enfoques de caracter 


\section{CELESTINESCA}

estético, estilístico, psicológico, crítico, literario, etc., completen la definición adecuada de todo su contenido.

Es, pues, absurdo pretender--continúa--que un mero análisis parcial pueda resolver, por si solo, los principales problemas de "La Celestina" y considera, en consecuencia, admisible y aun fecundo que el especialista se extienda a considerar aspectos que se salen del estricto marco de su trabajo.

Amparados pues, en tan liberal $y$ generoso criterio cabe contemplar la Tragicomedia de Calixto y Melibea, dejando de lado la controversia sobre si es novela u obra dramática, desde el punto de vista del texto convertido en espectáculo, que no otro es el del director de escena. Y al hablar de espectáculo no me refiero solamente a sus aspectos formales o visuales, sino a esa sutil transformación que sufre el lenguaje cuando está escrito para ser leido en recoleta soledad o, por el contrario, para ser escuchado y comprendido con carácter de inmediatez y urgencia por un auditorio generalmente heterogéneo al que hay que tratar de llevar a una identidad de sentimientos y emociones. Ello es lo que hace, precisamente, que el teatro sea una expresión literaria de tan peculiares y solas caracteristicas. Hay que establecer, pues, un ponderado equilibrio entre lo que se debe decir para la mejor definición del contenido y lo que es preciso contar para el necesario interés de la representación.

Contemplados en su totalidad los 16 actos, 021 si se prefiere de la Tragicomedia, la primera consideración es que se va a cometer una tropelia al tratar de condensar en algo más de 2 horas toda la ingente cantidad de pensamientos, ideas, conceptos y sabiduría contenidos en el texto. Desde un punto de vista literario, filosófico, crítico o histórico la tarea se nos antoja imposible. Desde el punto de vista del director con atencion fundamental a los ritmos, situaciones, intensidades y desarrollo de los personajes el empeño se posibilita en alguna medida.

Se trata, como queda dicho, de un problema de selección de la totalidad en atención a su valoración dramática. Problema que no es fácil resolver si tenemos en cuenta que son necesarios ciertos apoyos textuales referidos al mundo social en que los personajes se desenvuelven para que su "ser escénico", su caminar psicológico y, en definitiva su deambular trágica sea más fácilmente entendido. En cualquier caso y sea cual sea el criterio de objetividad que se aplique, creo que.la representación quedará necesariamente coja e incompleta.

En mi caso concreto, esta previa selección de textos y su acontecer escénico habia sido resuelta con anterioridad... La adaptación sobre la que trabaje era de Alejandro Casona y sus grandes condiciones de hombre de teatro--cualidad, en mi criterio, innegable en el mencionado autor-facilitaron en gran medida el trabajo dramatúrgico de mi puesta' en escena. 


\section{CELESTINESCA}

Intencionadamente di como buena la versión ya que me fue encomendado su montaje con gran premura de tiempo. En una sola ocasión pude intercambiar ideas con él, ya que se sometió a una delicada operación dias antes del primer ensayo y falleció la semana anterior al estreno en la Bienal de Venecia. Posteriormente introduje algunas modificaciones, tales, por ejemplo, como visualizar la escena entre Elicia y Crito, en casa de Celestina, nunca hasta entonces hecha o la de sugerir a modo de evocación la presentación de Celestina en el escenario o el planto de las meretrices jurando venganza con ocasion de su muerte. Para ello fueron necesarias algunas modificaciones del texto que no afectaban grandemente a la narración.

$Y$ ya que de ello hablamos y aun cuando no sea objeto fundamental de esta comunicación creo que seria muy interesante estudiar la relación Adaptador-Director y los problemas y consecuencias que se derivan de ella.

Antes de entrar en el análisis pormenorizado de espacio escénico, personajes y conflicto de la Celestina quisiera llamar la atención sobre la crisis del siglo XV como contexto social en el que se desarrolla la acción y en el que están inmersos sus protagonistas. A mi me sirvió en gran manera su estudio y a ella referi gran parte de mi trabajo. Fue de gran utilidad, a ese respecto, la lectura del citado libro de Maravall. La primera consecuencia que saqué fue la de que las tensiones y cambios sociales producidos en aquella sociedad eran resultado de una cultura urbana. Pese al caracter popular de sus personajes no asoma la menor rusticidad en el ambiente.

Es la ciudad, precisamente, el espacio donde vienen a acontecer los episodios de la Tragicomedia y todos sus personajes con diferentes calidades $y$ sea cual fuere su estamento social responden a las caracteristicas del momento.

Esta consideración me llevó a la idea, que finalmente fue casi necesidad, de trabajar sobre un espacio escénico de "interiores." Era, sin duda, difícil empeño dada la gran cantidad de lugares de acción necesarios para el desarrollo de la obra y los continuos cambios de uno a otro, con lo que se arriesgaba romper el ritmo de la representación y con ello la pretendida atención del público.

Otra reflexión me hizo insistir en este planteamiento; como ya apunté al hablar del texto, necesariamente habiamos de prescindir de muchos pasajes necesarios, o por lo menos convenientes, ¿por que no tratar de explicitar, siquiera en pequeña medida algunas de esas carencias mostrando el intimo entorno vital de los personajes?

Se trataba, pues, de sustituir con la elocuencia de las imágenes la falta de otro tipo de información. 


\section{CELESTINESCA}

Decidido que ése podia ser un buen camino,: Manuel Mampaso concibió un complejo espacio en. el que, sobre la base de una estructura urbana fija se movian con precisión los diferentes ambientes de Celestina, Melibea, Calixto o Areúsa. El huerto de Melibea fue sustituido en las dos últimas escenas por una alta torre--uno de los elementos fijos del decorado--, para dar mayor verosimilitud a la muerte de los amantes; la puerta de su primera cita se trasladaba al centro del escenario y las escenas con Celestina tenian lugar en el interior de la casa.

Se barajaron diferentes estéticas y finalmente el crudo realismo de la obra fue determinante, si bien fueron precisas algunas simplificaciones. Tales, por ejemplo, el interior de Areusa resuelto con una simple cama y ambiente luminico.

En lineas generales puede decirse que es Calixto quien provoca el conflicto y con su provocación arrastra en un encadenamiento muy actual de causas y efectos al resto de los personajes, todos ellos dibujados con tal precisión que, aun ahora, parecen seres tan vivos, tan de carne y hueso como lo fueron con ocasión de su alumbramiento.

Dos grupos sociales van a entrar en conflicto. Pertenecen al primero Calixto, Melibea, Alisa y Pleberio, personaje éste último de escasa entidad dramática pero de primera magnitud sociológicamente considerado. $Y$ al segundo grupo, Celestina, Pármeno, Sempronio, Elicia, Areúsa y Lucrecia.

Empezaré por los dos protagonistas.

La relación amorosa entre Calixto y Melibea fue tratada en mi montaje como el discurrir lógico de una pasión, de la que intencionadamente se obvia cualquier circunstancia que impida, o simplemente distraiga, su realización inmediata. Se ignoró cualquier alusión a la condición de converso de Calixto, según algunos estudiosos, o Pleberio, según otros, como impedimento para el matrimonio entre los dos amantes. Es teoría ésta innecesaria, dada la filosofía del amor que los condiciona. Simplemente no se casan porque no se lo han planteado como meta.

Siendo el amor un sentimiento permanente a lo largo de la historia de la humanidad, se manifiesta de modo diferente según la época en que se produce. En la que ahora nos interesa el matrimonio era el fin lógico según el orden establecido. Pero los amantes están inmersos en la cultura del amor y la vida, según la cual se aspira fundamentalmente a alcanzar el "soberano deleite," el placer. Se empieza a tener una concepción subjetiva del amor que induce a los seres, cualquiera que sea su condición social, a buscar como última consecuencia la plenitud.

En el texto hay abundantes referencias a lo dicho y llegan desde los mas diferentes estamentos. Por otra parte, a fuerza de sublimar esa 


\section{CELESTINESCA}

condición subjetiva, individual y libre del amor humano, llega a confundirse con el divino. Pero en el caballero, además, el amor es casi una ocupación, un deporte. Alejado de los trabajos y menesteres, y aún la guerra, que en épocas anteriores le distraian; en algo tiene que ocupar sus ocios.

$Y$ es precisamente ese concepto del amor como fuerza libre y desordenada, desobediente al sistema moral tradicional el que conduce a los amantes a su única posible salida: la muerte.

Como ya he dicho, dentro de estas coordenadas fundamentales desarrollé la historia amorosa. La conducta de sus protagonistas, asi considerada, es lógica y transcurre sin alternativas, aunque en el caso de Melibea tiene gran influencia su relación con Celestina según veremos.

En su primer encuentro, la alcahueta consigue transformar la furia de Melibea en interés por Calixto "Tanto me fué su habla enojosa--dirá mas tarde la doncella--cuanto después que tú me le tornaste a nombrar, alegre." Asi queda la puerta abierta para una nueva entrevista. En efecto Melibea manda venir a Celestina y le confiesa su pasión por Calixto en una escena fundamental de la obra, llena de sabiduria y conocimiento del ser humano. Es admirable el tratamiento de Rojas a este nuevo encuentro entre la hechicera y su señora. ¡Qué sutil transformación en los personajes! ¡Qué cambio de autoridad moral entre las dos mujeres! Celestina acaba siendo dueña de la situación en tanto que Melibea, llevada por su ardiente deseo, queda a merced de la vieja puta. Comienza a aflojarse su vergüenza, a quebrarse su pudor y solicita de su "fiel secretaria" que traiga a Calixto a la puerta del huerto.

Ya está todo el trabajo hecho y Celestina deja que sean a partir de ahora los amantes quienes conduzcan su propio destino.

En el huerto, en plena exaltación, Melibea promete satisfacciones sin cuento a Calixto y maldice de la puerta y fuertes cerrojos que impiden su gozo y "sin los cuales ni tu estarías quejoso ni yo descontenta." Cita a Calixto para el día siguiente a la misma hora y le despide con un turbador "Ordena de mi a tu voluntad."

Cuando a la noche siguiente Calixto saborea la posibilidad de materializar sus deseos es ya tarde para dar marcha atrás.

"Señora--dice el amante--si en conseguir esta merced toda mi vida he gastado, ¿Qué seria cuando me la diesen desecharla? $\mathrm{Ni}$ tú me lo puedes mandar ni yo obedecer. Nadando por este fuego de tu deseo toda mi vida, ¿no qujeres que me arrime al dulce puerto a descansar de mis pasados trabajos?"

Melibea ha ido demasiado lejos y el caballero no soltará su presa. Es el principio del fin. 
En cuanto a los interiores de Calixto y Melibea, más intencionado si cabe el primero, quisimos evidenciar--como ya se dijo al hablar del espacio escénico--el lujo, el bienestar material y aun el ocio de una clase burguesa adinerada sin otra preocupación que la de gastar para adquirir respeto y consideración social. $\mathrm{Ni}$ una mesa de trabajo, ni un libro de estudio provechoso, ningún objeto presente que pudiera inducirnos a pensar en una ocupación seria por parte de su morador.

Pasemos ahora, al segundo grupo en conflicto, esto es, a los personajes que configuran el mundo celestinesco.

Si no existiera el Quijote--dice Maravall--seguramente sería Celestina nuestro mito más universal. La enorme complejidad de este personaje impide abordarlo tanto linealmente como en la totalidad de su riquísima psicologia.

Celestina obedece en la obra de Rojas a los condicionamientos de la época y su brillo reside precisamente en el sometimiento a un "estatus" que la modela con múltiples facetas. Su contenido humano es enorme, su sabiduria popular vastísima y su conocimiento del mundo que la rodea muestra una agudeza de ingenio poco común.

Milagros Leal, gran creadora del personaje de mi versión, y yo, tuvimos múltiples cambios de impresiones sobre los aspectos y caracteristicas del personaje que convenia destacar fundamentalmente.

En cuanto a su aspecto físico, estábamos muy de acuerdo en mostrarlo conforme a algunas de las alusiones del texto. Así en su primer encuentro con Melibea dice ésta: "Vieja te has parado. Bien dicen que los dias no pasan en balde. Asi goce de mí, no te conociera, sino por esa señaleja de la cara. Figuráseme que eras hermosa. Otra pareces; muy mudada estás." Y Celestina: "Señora, ten tú el tiempo que no ande y tendré yo mi forma que no se mude. ¿No has leído que dicen: vendrá el dia en que al espejo no te conozcas?"

Más adelante, con ocasión de su enfado Melibea la llama "desvergonzada barbuda." Y Sempronio viéndola llegar a casa comenta: "que despacio llega la barbuda." Pármeno habla de sus seis docenas de años y ella presume de haber bebido y gozado sin medida en mejores tiempos. Todo ello, unido a su precaria economia, a su dificil subsistir y al entorno social en el que vive--no en el que trabaja--nos sugiere, sin duda una imagen muy deteriorada y con evidentes signos de depravación.

Otro aspecto del personaje que me interesó destacar fue su profesionalidad. Celestina tiene conciencia de que está ejerciendo un trabajo; precisamente el que le ha tocado realizar en la vida. Y a él se entrega en cuerpo y alma, sin regatear ningün esfuerzo ni sacrificio. Tiene su propia moral y vive de acuerdo con ella. 


\section{CElestinesCA}

"Es mi oficio--dice en alguna ocasión--procurar el bien de los demás." Precisamente por ese sentido del trabajo remunerado no quiere dar parte de la cadena a Pármeno y Sempronio. Ella se lo ha ganado. $Y$ cuando ambos la piden para arreglar sus maltrechas armas, los envia a su dueño. "¿Qué tiene que ver mi galardón con tu salario?" En la misma escena antes de matarla la amenazan con publicar quien es, y responde: "¿Quién soy yo, Sempronio? Una vieja como Dios me hizo, que vive de su oficio como cada cual del suyo, muy limpiamente. A quien no me quiere no le busco. De mi casa me vienen a sacar." Otras muchas referencias avalan esta idea pero considero innecesario traerlas a colación.

A menudo se la nombra en la obra de hechicera $y$, aunque brevemente, no quiero pasar por alto esta condición. La magia renacentista ha sido considerada por algunos como un embrión de la ciencia moderna. La alquimia se convertirá en quimica, la astrologia en astronomia, la herejia en filosofia, y la magia despojada de su ropaje medieval, no es otra cosa que la ciencia.

La magia adquirió gran auge durante el renacimiento en la medida en que se negaba la existencia real de brujas. De ahi que no convenga confundir los tèrminos "hechicera" y "bruja."

En la escena del conjuro, Celestina no practica un rito demoniaco sino que practica un arte, ejerce un oficio: el de hechicera. No se entrega a aquelarres ni a ritos histéricos sino que trabaja como en la rebotica con cosas fisicas, naturales, en cuyas propiedades cree. Hasta Plutón puede considerarse como uno más de los elementos que intervienen en la mecánica del conjuro. Lo fundamental aqui es que Celestina necesita creer en sus hechicerias. No las practicaria si no creyera que determinadas causas producen los efectos apetecidos. Pero dejando a un lado estas especificas connotaciones, Celestina se incluye en un grupo, social perfectamente caracterizado y definido en el que la acompañan criados y pupilas.

Hemos hablado de una clase burguesa adinerada y ociosa a la que pertenece Calixto. A la sombra de esta clase surge otra de segundo grado que obedece por mimetismo a las caracteristicas de la primera; es la de los servidores o criados. En general son utilizados por el señor para mostrar su poder económico y social. Su cometido es, simplemente, el de acompañarle, sin trabajos especificos que realizar. Se trata, pues, de un estamento social humilde, también ocioso y desvinculado de los intereses del amo. A esta condición pertenecen Pármeno y Sempronio.

En principio, el criado era un miembro de la casa, a la que le ataban lazos de deberes morales. Era considerado casi como de la familia y en el dueño encontraba protección y amparo. Incluso se heredaban de padres a hijos. Esta circunstancia se prolongará por más tiempo en ambientes rústicos. Pero en la ciudad, la vinculación fue cediendo y su 


\section{CELESTINESCA}

"status" se modificó hasta llegar a ser un șimple asălariado. Al romperse los lazos afectivos y morales solo les une un contrato laboral. $Y$ ya que, al igual que los señores, también desean como fin primordial ganar dinero no es raro que intenten sacar provecho de cualquier situación. Sin embargo aparecen en Pármeno vestigios de aquella clase servidora aun ligada afectivamente a. su señor, cuyo interés antepone al suyo propio. Celestina le hace ver con aguda malicia el verdadero estado de su situación. Está en casa de Calixto, pero no es de ella. 'Y cuando mas tarde le tienta para que se le una en el negocio de Calixto, responde Pármeno:

"Riqueza deseo; pero quien torpemente sube a lo alto más pronto cae que subió. No querría bienes mal ganados." Actitud que contrasta con la de Sempronio que pretende salir de la pobreza aun a costa del remedio de su amo: "Deseo provecho--dice--querría que este negocio tuviese buen fin" y más adelante: "procuremos provecho mientras pendiere su contienda."

Pero la actitud del joven criado cambia al final del $2^{\circ}$ acto y es Calixto quien provoca esta mutación al maltratarle despóticamente, solo porque intenta ponerle en guardia contra Celestina. Para mi, es uno de los momentos claves del personaje y aun de la obra. Oigamos a Pármeno después de ser golpeado por Calixto: "OOh desdichado de mi!" Por ser leal padezco mal. Otros se ganan por malos y yo me pierdo por bueno. ¿Asi es el mundo?. Pues ir quiero al hilo de la gente. Si hubiera creido a Celestina con sus seis docenas de años a cuestas no me maltratara Calixto. Mas esto me pondrá escarmiento de aquí en adelante con él. Si dijera "comamos," yo también. Si quiere quemar su hacienda, ir por fuego. Destruya, rompa, quiebre, dañe lo suyo, que a mi, parte me tocará, pues bien dicen: a río revuelto ganancia de pescadores. ¡Nunca más perro a molino!"

A partir de aqui los dos criados obran de consumo y se suman a la grey--Sempronio ya lo estaba--del mundo celestinesco. Otros conocidos personajes integran este mundo: son las figuras de Elicia y Areúsa y obedecen a las mismas leyes sociales que el resto.

Como ocurre con Pármeno y Sempronio, estas dos pupilas de Celestina, aun de características similares, tienen matices que las diferencian. Elicia vive con Celestina, a quien muy posiblemente ayude en sus menesteres y dé quièn está apreñdiendo un arte, un oficio. Su fin lógico es suceder a la "madre" cuando éstā falte.

Areúsa, por el contrario, mora aparté y su aspiración es la de llegar a ser "señora," por lo menos, vivir según las costumbres de. las demás. De ahi que las más acerbas criticas hacia Melibea salgan de su boca, y dejen traslucir, por su virulencia, un asomo de envidia hacia lo inalcanzable. En el acto $9^{\circ}$ la oimos refiriéndose a ella: "Pues no la has 


\section{CELESTINESCA}

visto como yo, hermana mia. Dios me lo demanda, si en ayunas la lopases, si aquel dia pudieses comer de asco. Todo el año se está encerrada con mudas de mil suciedades. Las riquezas las hacen a estas, hermosas, que no las gracias de su cuerpo. Tienen unas tetas, para ser doncella, como si tres veces hubiese parido, no parecen sino dos grandes calabazas. El vientre no se lo he visto; pero juzgando por lo otro creo ya que lo tienen tan flojo como vieja de cincuenta años."

Y cuando Sempronio alude al alto linaje de los enamorados, responde Areúsa: "Ruín sea quien por ruin tiene. Las obras hacen linaje, que al fin todos somos hijos de Adán y Eva. Procure cada uno ser bueno por si mismo y no vaya a buscar en la nobleza de sus pasados la virtud." Otra circunstancía diferencial entre las dos es que Elicia se prodiga sin tasa. Areúsa pretende vivir de un solo amante a quien aparentemente respeta.

Areusa:

¿Que quieres que haga? Sabes que se partió aquél mi amigo con su capitán a la guerra. ¿Había de hacerle ruindad?

Celestina: ¡Verás que daño y que gran ruindad!

Areusa: $\quad$ Si lo seria. Que me da todo lo que he menester, tiéneme honrada, favoréceme y trátame como si fuese su señora. [enfasis mio]

Celestina le reprocha esta actitud poniendo como ejemplo a su compañera: "Si vieses el saber de tu prima y cuanto le han aprovechado mis consejos y crianza y que gran maestra está! Uno en la cama y otro en la puerta y otro que suspira por ella en su casa se precia de tener. $Y$ con todos cumple y a todos. muestra buena cara; y todos piensan que son muy queridos y cada uno piensa que no hay otro y que él solo es el privado y el que le da lo que ha de menester." Este pequeño cosmos, necesitaba de una expresion escénica formal, precisamente como contraste con la belleza y elegancia de los ambientes de la clase poderosa.

Los momentos en que mejor se manifiesta.la pobreza moral de sus componentes, entre ellos el espeluznante de la muerte de Celestina a manos de los criados, tiene lugar en su casa, en su propio ambiente: de ahi que prestáramos especial atencion a este decorado que debia sugerir todo el complejo contenido sicológico de su moradora......

Como ya se ha dicho, la habitacion, con Celestina en ella, surgia como evocada desde el fondo del escenario mientras la luz se iba perfilando sobre ella muy lentamente. Alli calderos y alambiques. azumbre y redomas, braseros, frascos de potingues, virgos y rosarios. ollas, exvotos, imagineria maltrecha y alguna piel en la pared útil para ciertos menesteres, cintas, aparejos, una rueca arrinconada y muchos mas 


\section{CELESTINESCA}

objetos nos mostraban el quehacer cotidiano de la.alcahueta. Hasta Elicia, con Crito, retozaba en el sobrado.

Ese es su universo: donde ella vive, goza, manda y gobierna. Los otros ambientes son algo ajeno donde se muestra servicial, humilde, diligente è hipócrita.

En mi opinión el contraste facilita la tarea interpretativa pues manifiesta más claramente la dualidad de Celestina entre el ser y el parecer. Sus mentiras se hacen palmarias; su simpatia, una necesidad; su bondad, hipocresia; su virtud, egoismo desaforado. Celestina no es simpática, agradable o placentera. Quienes la han visto en su propio ambiente saben que esa es una actitud adoptada porque hay que vivir. $Y$ la vida, al mismo tiempo que un largo recorrido de placeres, buscados con ansiedad, es dificil. $Y$ la muerte es mala, simplemente, porque interrumpe la posibilidad de seguir gozando.

Muchas cosas han quedado por decir, como adverti previamente. Mi tiempo se ha cumplido y sólo me resta agradecer a los organizadores de estos actos la gentileza de haberme invitado a participar en ellos.
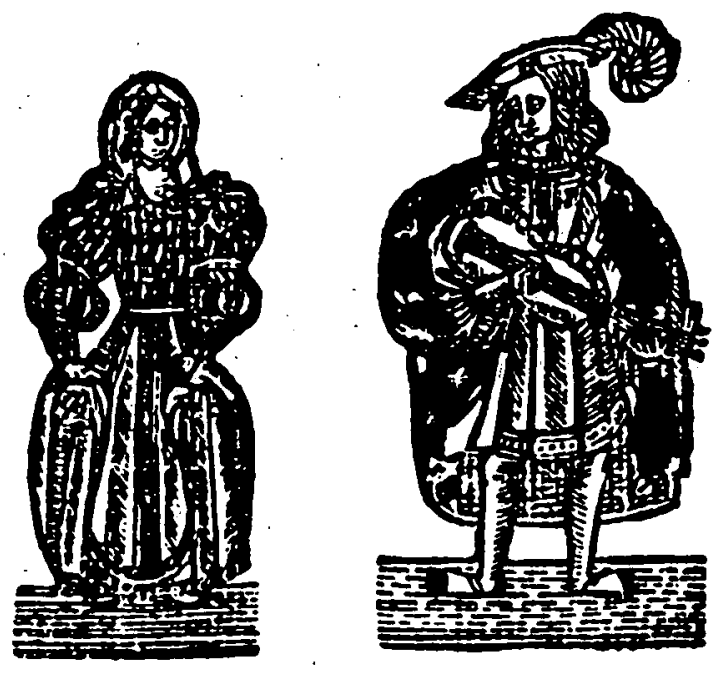